\title{
Research on the Effectiveness Evaluation Model of the Prison Physical Protection System Based on Grey Analytic Hierarchy Process
}

\author{
Ke Yin \\ Department of Public Security, Nanjing Forest Police College, Nanjing, China \\ Correspondence should be addressed to Ke Yin; yinkeke@sina.com
}

Received 28 August 2017; Revised 11 November 2017; Accepted 16 November 2017; Published 12 December 2017

Academic Editor: Vincenzo Conti

Copyright (C) 2017 Ke Yin. This is an open access article distributed under the Creative Commons Attribution License, which permits unrestricted use, distribution, and reproduction in any medium, provided the original work is properly cited.

In order to improve the rationality and validity of the physical protection system effectiveness evaluation in prison, this paper discusses the main factors that affect the system performance in the prison security system construction process and explores the key points in evaluating the effectiveness of searching system. The author of this paper has constructed an evaluation index system that accurately reflects the physical protection system in prison and comes up with an evaluation model and algorithm based on the gray level analysis by verifying the rationality of effectiveness evaluation model of prison physical protection system and the validity of the evaluation method.

\section{Introduction}

The concept of effectiveness evaluation, first proposed by the US Navy on the combat system, refers to the evaluation of both the index of how required tasks are completed within a specified time and probabilities that the system will satisfy the combat needs under specified conditions and within a specified time. To define performance, Gallegos (a professor of Massachusetts Institute of Technology) and Bonano [1] argued that it was the matching degree of the system with the mission. And by the year 2009, the US Industry Weapons Effectiveness Advisory Committee (WSEIAC) defined it as a measure of the system's ability to meet a set of specific task requirements and a function of its availability, credibility, and inherent competence [2]. Since then, the effectiveness evaluation tended to be exploited in the military field $[3,4]$ to assess the pragmatic effect of command and weapon system. Its killer feature was accuracy and promptness when it was targeting a particular group of people or events.

Prison security is a special physical protection system under a special circumstance, the quality of which has direct links to the success of the prison work. At present, the new technology continues to penetrate the security field and to some extent has changed the traditional physical protection system architecture and business management model. Therefore, prison physical protection system has undergone tremendous changes with the wide application of new technologies, such as the network technology and the intelligent control technology. Since prison is a special social venue, the construction of its physical protection system is also particularly important. Currently, the vast majority of prisons have established a three-dimensional guard (3DGuard) zone of electric power grid with electronic fences and $\mathrm{AB}$ door for the protection of the main body as its main body of perimeter prevention. This kind of prison is usually equipped comprehensively with video surveillance, eavesdropping, access control systems, intercom systems, face recognition systems, and alarm systems so as to fulfill the information exchange and resource sharing of each security business system in the prison. However, most prisons are overloaded; that is, the total number of prisoners remains high with an increasing trend [5]. In that case, it is urgently required to have an effective measure to determine the effectiveness of the current physical protection system and identify the weakness.

Although the effectiveness evaluation method has been maturely applied in the military field for so long a time, 
there are few studies on its application into the physical protection system. This research mainly focuses on two aspects: one is based on the path analysis derived from the adversary sequence diagram model, whose main object is the critical area of unidirectional path, such as nuclear power station [6-8]. It is usually conducted in a conceived indoor situation where there are multiple unidirectional paths, the end of which is still the same internal target area. Such a model is apparently influenced by the effectiveness evaluation in the field of military research but cannot be effectively employed in many areas of physical protection system, such as thronged metro transfer stations or prisons with complex internal structures, where the assessment should take into account not only the path of entry but also the possibility of being broken-in from outside. The other aspect of this paper will be mainly on the exploration of the establishment of effectiveness evaluation index of physical protection system, such as $[9,10]$. It is widely argued that some of these models ignore the uniqueness of the physical protection system, which indicates that the model needs to be adapted to some extent to meet the requirement of different environments. In fact, the problem is that it cannot be used to make operational simulation by applying the effectiveness evaluation index through modeling to the specific physical protection systems. So it is difficult for us to obtain adequate data to support.

What is more, it is quite lately that people pay attention to the researches on the integrated prison physical protection system. And very few researches have been made on its effectiveness evaluation. Hongtao [11] points out in his research that though some researches on the safety of prison security protection systems have been made, the current prison security protection systems, to much extent, are seriously impractical, irrational, and incomplete due to the complexity and the specialty of the construction and the lack of comprehensive knowledge of particular requirements. All these shortcomings will definitely bring destructive disaster to the whole security system in prison.

Therefore, we need to explore the typical application of the physical protection system in prison, analyze the subtle possibilities and availabilities of its effectiveness evaluation, and construct the corresponding effectiveness evaluation indicator system for the prison physical protection system. This research, based on the former researches of effectiveness assessment in security protection and other relative areas, aims to make an integrative analysis of some assessing indicators commonly used in the security protection system researches together with the special needs in prison security protection, constructing a practical effectiveness evaluation indicator system for prison security protection so as to enhance the accuracy and feasibility of the system in practical uses.

\section{The Content Analysis of the Effectiveness Evaluation of the Prison Physical Protection System}

The physical protection system, as a typical electronic equipment communication and processing system constructed on the basis of the Internet of Things mode, is highly complex as it covers aspects from risks, security, and communication to equipment. And the prison physical protection system, for its unique environment and functional requirements, is different from the conventional physical protection system. It includes not only the general content of the physical protection system assessment, but also the analysis of the possibility of external invasions and sudden bursts of internal breakouts. An effective evaluation model usually should contain the elements such as (a) a comprehensive reflection of the system's real state, (b) case analysis of difference events, (c) filtering out as many subjective factors as possible, and (d) repeated verifications [12].

Based on the above understanding, this paper divides the factors influencing the effectiveness evaluation into three levels: the first level includes three key elements of the physical protection system: Detection, Reaction, and Delay; the second level is related to the relevant intelligent computer processing technologies, and the third is the maintenance and update of security equipment.

As a dynamic physical protection system, the prison physical protection system is possessed of both static and dynamic properties. If we only consider a single attribute, it will be difficult, in terms of comprehensiveness evaluation, to overcome the limitations. Therefore, we must first regard the effectiveness evaluation of the prison physical protection system as both a dynamic and static system, considering its static attributes while taking into account its dynamic properties when the system is operating so as to have an assessment as comprehensive as possible. So it is quite a complicate systemic engineering to set up an effectiveness evaluation indicator system for the security protection in prisons. Some principles such as systematicness, objectivity, comparativeness, comprehensiveness, purpose, and operability need to be strictly followed [13]. According to Guizhi [14] and Argenti et al. [15], there are three key factors influencing the results of the effectiveness evaluation to prison physical protection system. The first is Informalization in the protection system, which is regarded as a key factor to affect the information transition and feedback between the front-end equipment and the back-end equipment. The second is action efficiency, which refers to the ability of administration personnel to obtain and apply the information from the front-end equipment. And the third key factor refers to sustainability of the system.

In order to enhance the effective protection of security systems, some adjustment must be made based on the practical operation and actual environment after the comprehensive administrative system is loaded so as to further promote the protective ability and administrative effects. In this process, we often regard the stability as static factor and the execution as dynamic factor. So the above three factors have become the indicators commonly used in building any protective system management. In this research, we also selected these three factors in establishing the basic process of prison physical protection system management (see Figure 1). 
TABLE 1: Effectiveness evaluation index system of the prison physical protection system.

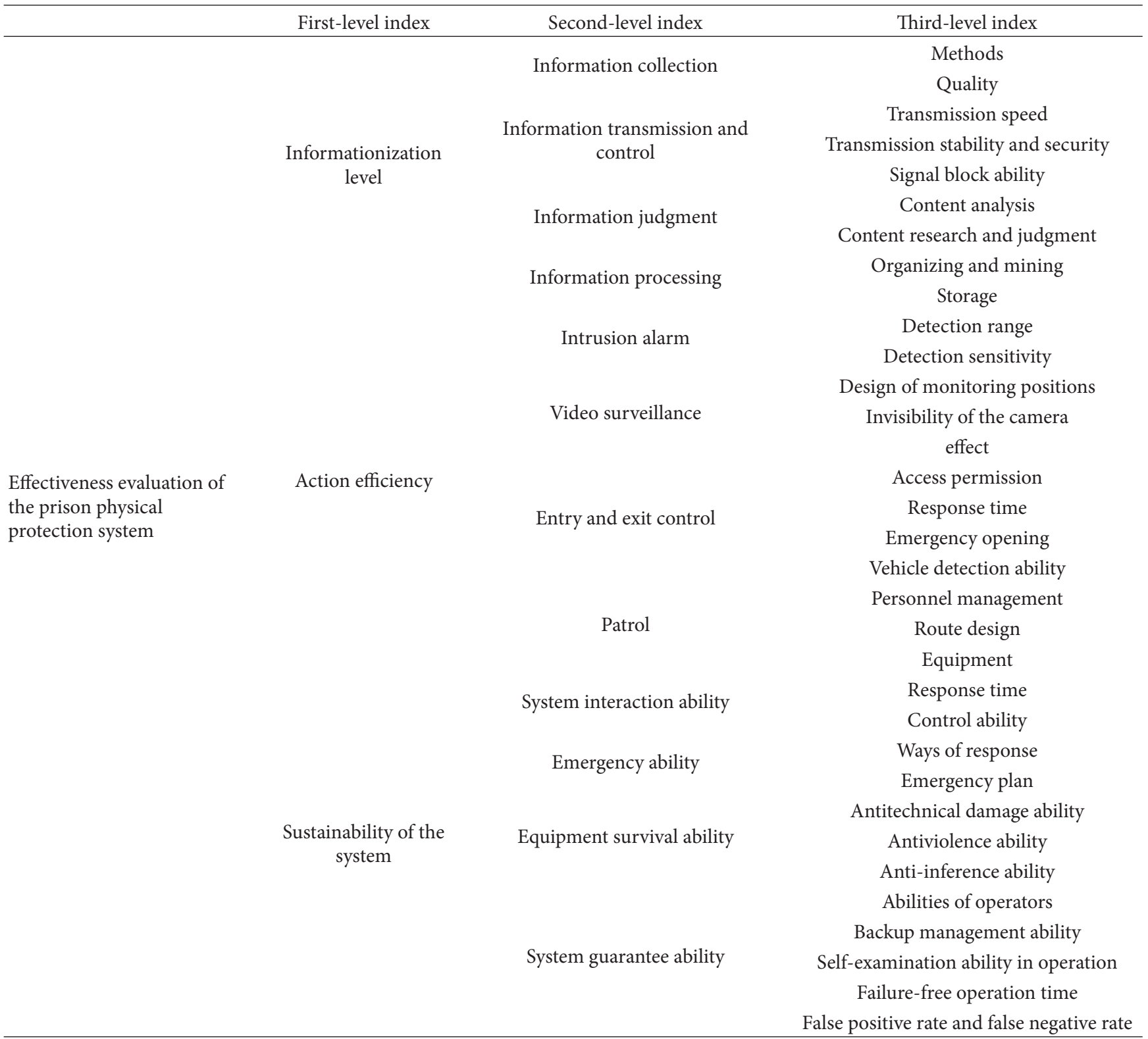

\section{Analysis of Effectiveness Evaluation Index System of the Prison Physical Protection System}

Prison physical protection system not only involves video surveillance, perimeter prevention, control of entry and exit, intercom, emergency alarm, electronic patrol, intelligent analysis, electronic maps, and many other security features but also needs to be integrated with the police management system, information research, and judgment system and command system. Therefore, the construction of the assessment system of the prison physical protection system should be grounded on not only the basic assessment model of the physical protection system, but also the special needs of the specific functional venues, such as the prison. According to the effectiveness evaluation content of the prison physical protection system, we set up the evaluation index system in Table 1.

3.1. The Informationization Index of the Prison Physical Protection System. The informationization index of the prison physical protection system is a comprehensive index which reflects the level of its information transmission and control, and it is a typical hierarchy evaluation system. As main command means of the modern physical protection system, the information system of the prison security will, to a large extent, determine the whole system's quality and performance by its sole performance. This index, through the evaluation of the main functions of the prison security information system, reflects its technical performance in 


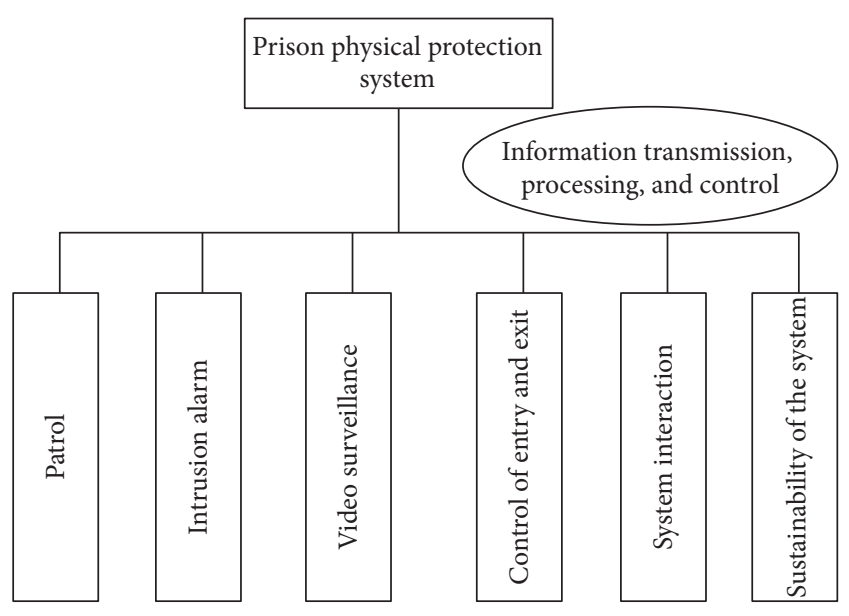

FIgURE 1: Prison physical protection system.

both alarming and disalarming state. It mainly includes the functions of information collection, transmission, judgment, processing, and control of the prison physical protection system. Information collection focuses on the methods of information acquisition and the quality and timeliness of data information. Information transmission examines the communication condition and transmission efficiency of the prison security information system. Information control focuses on the interference and shielding of information transmission on specific channels or frequencies in the prison; and the information judgment mainly examines the application of prison security information system in aiding analysis, research, and judgment of data information. Information processing puts emphasis on assessing the ability of automatic organization, identification, and integration of information and the ability to generate corresponding judgment results. The informatization performance of the prison physical protection system can be accurately evaluated by stable operation time, failure rate, and accuracy rate and result in a good testability and operability.

\subsection{Action Efficiency Index of the Prison Physical Protection} System. The action efficiency index of the prison physical protection system mainly reflects the static and the dynamic attributes of the prison physical protection system, focusing on the monitoring effect produced by the prison physical protection system. This index focuses on the effect of the major monitoring activities when the prison physical protection system is operating and serves as a basis for assessing the overall monitoring effect of the whole system. The assessment mainly includes four basic links of the physical protection system: the intrusion alarm, the video surveillance, the entry control, and the patrolling. These four links also involve three key elements of Detection, Delay, and Reaction. Generally, the video surveillance is the core of the physical protection system. However, within a special sensitive venue such as prisons, some other aspects of its physical protection system are equally important, and any weakness in each link will cause the failure of the whole system. (a) The intrusion alarm covers not only the external invasion in the perimeter defense, but also the outbursts of internal breakouts. It focuses on the examination of the covering range and sensitivity of various intrusion detectors. (b) The video surveillance index assesses the covering range of the video, the invisibility of the cameras, and the clarity of the videos. (c) The index of entry and exit control is divided into two parts: the access control of the personnel and that of the vehicle. It mainly examines the access permission, the time spent during the access, the emergency opening and closing of entry and exit during sudden events, and the inspection of life signs in the vehicle. (d) The patrol index is mainly concerned with patrol staff management, patrol route design, and staff equipment configuration. Here the patrol staff management refers to the pairing and time rearrangement. The patrol route design is based on the patrol personnel, covering critical and vital areas. The staff equipment includes solo emergency equipment in the environment of prison.

In the test phase, there are a number of indexes to display the system's prevention ability, so we can, depending on the actual situation, choose the index of greatest impact on the system prevention ability and the highest sensitivity as the key test object. In the operating phase, we can combine qualitative and quantitative methods to test the index of system prevention ability to provide practical data to reach the system's prevention goals.

\subsection{The Sustainability of the System Index of the Prison} Physical Protection System. The sustainability of the system index is mainly embodied in the interaction ability between subsidiary systems, the response time, and the ability for the system to work unstoppably all day round, such as the interacting between video surveillance and intrusion alarm system, fire control system, entry and exit control system, intercom system and emergency alarm to automatically identify and ring the alarm adaptability, the fault-tolerant and repair ability, and the recoverability after it starts operating. The security equipment is an important part of the physical protection system and the failure of which will lead to the loss of its prevention ability and further affect the performance of the whole system. And the system guarantee ability index is more concerned with the maintenance of the system by its user in the integrated management system of prison security, including equipment backup, technical support, and system failure identification. Improving the survival ability of the system will not only guarantee the benefits from investment, but also give a better display of its advantages in prevention.

\section{Applied Research on the Effectiveness Evaluation Model of the Prison Security Based on Grey Analytic Hierarchy Process}

4.1. Assessment Model and Algorithm Based on Grey Analytic Hierarchy Process. Grey Analytic Hierarchy Process (GAHP) is an analytic method utilized to construct the hierarchy and index weight of the assessed object and to calculate the comprehensive evaluation value with the grey number 
and the whitening weight function in the grey theory. This method is suitable for the evaluation of objects which has a prominent hierarchical structure and whose index is difficult to quantify. Therefore, this paper chooses this method to solve the problem of effectiveness evaluation of the prison physical protection system. According to the hierarchical effectiveness evaluation index system of the prison physical protection system, we can make the following settings.

First-level index set is

$$
A=\left\{A_{1}, A_{2}, \ldots, A_{i}\right\} \quad(i=1,2, \ldots, o) .
$$

First-level index weight set is

$$
\omega=\left\{U_{1}, U_{2}, \ldots, U_{i}\right\} \quad(i=1,2, \ldots, o) .
$$

Second-level index set is

$$
A_{i}=\left\{A_{i 1}, A_{i 2}, \ldots, A_{i j}\right\} \quad(j=1,2, \ldots, p) .
$$

Second-level index weight set is

$$
\omega_{i}=\left\{\omega_{i 1}, \omega_{i 2}, \ldots, \omega_{i j}\right\} \quad(j=1,2, \ldots, p) .
$$

Third-level index set is

$$
A_{i j}=\left\{A_{i j 1}, A_{i j 2}, \ldots, A_{i j k}\right\} \quad(k=1,2, \ldots, q) .
$$

Third-level index weight set is

$$
\omega_{i j}=\left\{\omega_{i j 1}, \omega_{i j 2}, \ldots, \omega_{i j k}\right\} \quad(k=1,2, \ldots, q) .
$$

where $A_{i j k}$ denotes the third-level assessment index and $\omega_{i j k}$ denotes its weight.

The assessment index system clarifies the affiliation between each index, but the importance of each index on the same hierarchy to its higher-level index still needs to be determined by scientific methods. Meanwhile, the hierarchical structure of the effectiveness evaluation index system of the prison physical protection system is preferable in the application of GAHP to calculate the weight value of each index element. This paper adopts GAHP to solve the problem of weight distribution. Its main idea is to use the 1-9 scale method [16] to score and compare the importance of index on the same hierarchy and then construct the judgment matrix according to the scoring and test its consistency. The judgment matrix needs to be reconstructed if it failed to meet the consistency requirements, and only when the requirements are met will the reconstruction stop.

The effectiveness evaluation indexes of prison physical protection system are for the majority qualitative, which cannot be directly quantified and therefore need to be converted into quantitative indicators. Setting the evaluation level can effectively deal with the quantification of qualitative indicators. According to the effectiveness evaluation criteria of the prison physical protection system, we set five levels, each level corresponding to an interval, as shown in Table 2.

Expertise is arranged to score the assessed indexes and set the score of the $S_{\text {th }}(s=1,2, m)$ expert to the assessment index
TABLE 2: Criteria of evaluation level.

\begin{tabular}{lccccc}
\hline Interval & $0 \leq \tau \leq 2$ & $2<\tau \leq 4$ & $4<\tau \leq 6$ & $6<\tau \leq 8$ & $8<\tau \leq 10$ \\
\hline Class & Bad & $\begin{array}{c}\text { Relatively } \\
\text { bad }\end{array}$ & Average & $\begin{array}{c}\text { Relatively } \\
\text { good }\end{array}$ & $\begin{array}{c}\text { Extremely } \\
\text { good }\end{array}$ \\
\hline
\end{tabular}

$A_{i j k}$ as $d_{i j k s}$. After we get the score of each expert by turns, the scoring matrix of the expert group is obtained:

$$
D_{i j}=\left[\begin{array}{cccc}
d_{i j 11} & d_{i j 12} & \cdots & d_{i j 1 m} \\
d_{i j 21} & d_{i j 22} & \cdots & d_{i j 2 m} \\
\vdots & \vdots & \ddots & \vdots \\
d_{i j k 1} & d_{i j k 2} & \cdots & d_{i j k m}
\end{array}\right]
$$

According to the score criteria, we establish five grey classes and the corresponding whitening weight function [17] as follows.

Class 1 is "extremely good" $(e=1)$, the grey number is $\otimes \epsilon$ $[0,9,+\infty]$, and the corresponding whitening weight function is

$$
\begin{gathered}
\frac{d_{i j k m}}{9} \quad d_{i j k m} \in[0,9] \\
1 \quad d_{i j k m} \in[9,+\infty] \\
0 \quad d_{i j k m} \notin[0,+\infty] .
\end{gathered}
$$

Class 2 is "relatively good" ( $e=2)$, the grey number is $\otimes \epsilon$ $[0,7,14]$, and the corresponding whitening weight function is

$$
f_{1}\left(d_{i j k m}\right)= \begin{cases}\frac{d_{i j k m}}{7} & d_{i j k m} \in[0,7] \\ 2-\frac{d_{i j k m}}{7} & d_{i j k m} \in[7,14] \\ 0 & d_{i j k m} \notin[0,14] .\end{cases}
$$

Class 3 is "average" ( $e=3$ ), the grey number is $\otimes \epsilon$ $[0,5,10]$, and the corresponding whitening weight function is

$$
f_{1}\left(d_{i j k m}\right)= \begin{cases}\frac{d_{i j k m}}{5} & d_{i j k m} \in[0,5] \\ 2-\frac{d_{i j k m}}{5} & d_{i j k m} \in[5,10] \\ 0 & d_{i j k m} \notin[0,10] .\end{cases}
$$

Class 4 is "relatively bad" ( $e=4)$, the grey number is $\otimes \epsilon$ $[0,3,6]$, and the corresponding whitening weight function is

$$
f_{1}\left(d_{i j k m}\right)= \begin{cases}\frac{d_{i j k m}}{3} & d_{i j k m} \in[0,3] \\ 2-\frac{d_{i j k m}}{3} & d_{i j k m} \in[3,6] \\ 0 & d_{i j k m} \notin[0,6] .\end{cases}
$$


Class 5 is "extremely bad" ( $e=5)$, the grey number is $\otimes \epsilon$ $[0,1,2]$, and the corresponding whitening weight function is

$$
f_{1}\left(d_{i j k m}\right)= \begin{cases}1 & d_{i j k m} \in[0,1] \\ \frac{3-d_{i j k m}}{2} & d_{i j k m} \in[1,2] \\ 0 & d_{i j k m} \notin[0,2] .\end{cases}
$$

Calculate the grey assessment coefficient of the assessed grey class under each assessed index according to the grey number and its corresponding whitening functions and obtain the total grey assessment coefficient $x_{i j k}$ ( $g$ is the number of grey classes):

$$
\begin{aligned}
& x_{i j k e}=\sum_{s=1}^{p} f_{e}\left(d_{i j k s}\right) \\
& x_{i j k e}=\sum_{e=1}^{g} x_{i j k e} .
\end{aligned}
$$

where $g$ is the number of the assessed grey classes.

The grey assessment weight value of the $e_{\text {th }}$ grey class is

$$
r_{i j k e}=\frac{x_{i j k e}}{x_{i j k}}=\frac{\sum_{s=1}^{p} f_{e}\left(d_{i j k s}\right)}{\sum_{e=1}^{g} x_{i j k e}} .
$$

Set each grey assessed weight vector under assessed index $A_{i j}$ as $R_{i j k}=\left(r_{i j k 1}, r_{i j k 2}, \ldots, r_{i j k g}\right)$ and the grey weigh value matrix of $A_{i j}$ is

$$
R_{i j}=\left[R_{i j 1}, R_{i j 2}, \ldots, R_{i j k}\right]^{T} .
$$

Comprehensive results of third-level index $A_{i j}$ : the calculation formula of assessment result is

$$
B_{i j}=\omega_{i j} R_{i j} .
$$

Comprehensive results of second-level index $A_{i}$ : calculate $R_{i}=\left[R_{i 1}, R_{i 2}, \ldots, R_{i n}\right]^{T}$, the grey assessment weight matrix of $A_{i}$ according to $B_{i j}$, and the assessment results of $A_{i j}$. The assessment result is

$$
B_{i}=\omega_{i} R_{i}
$$

Comprehensive results of first-level index $A$ : calculate $R_{i}=\left[R_{1}, R_{2}, \ldots, R_{m}\right]^{T}$, the grey assessment weight matrix of $A$ according to $B_{i}$, and the assessment results of $A_{i}$. The assessment result is

$$
B=\omega R .
$$

Assign each grey class the whitening value and set the scale value of each assessed grey class as $d_{t}(t=1,2, \ldots, g)$,

\begin{tabular}{|c|c|c|c|c|c|c|}
\hline $\begin{array}{l}\text { First- } \\
\text { level } \\
\text { index }\end{array}$ & $\begin{array}{c}\text { Second- } \\
\text { level } \\
\text { index }\end{array}$ & $\begin{array}{l}\text { Third- } \\
\text { level } \\
\text { index }\end{array}$ & $\begin{array}{c}\text { Expert } \\
\text { A }\end{array}$ & $\begin{array}{c}\text { Expert } \\
\text { B }\end{array}$ & $\begin{array}{c}\text { Expert } \\
\text { C }\end{array}$ & $\begin{array}{c}\text { Expert } \\
\text { D }\end{array}$ \\
\hline \multirow{9}{*}{$A_{1}$} & \multirow{2}{*}{$A_{11}$} & $A_{111}$ & 7 & 8 & 8 & 9 \\
\hline & & $A_{112}$ & 6 & 8 & 7 & 7 \\
\hline & \multirow{3}{*}{$A_{12}$} & $A_{121}$ & 7 & 8 & 9 & 7 \\
\hline & & $A_{122}$ & 8 & 7 & 8 & 9 \\
\hline & & $A_{123}$ & 7 & 7 & 8 & 7 \\
\hline & \multirow{2}{*}{$A_{13}$} & $A_{131}$ & 8 & 8 & 9 & 6 \\
\hline & & $A_{132}$ & 8 & 9 & 7 & 9 \\
\hline & \multirow{2}{*}{$A_{14}$} & $A_{141}$ & 7 & 8 & 7 & 9 \\
\hline & & $A_{142}$ & 6 & 7 & 8 & 7 \\
\hline \multirow{13}{*}{$A_{2}$} & \multirow{3}{*}{$A_{21}$} & $A_{211}$ & 6 & 8 & 7 & 7 \\
\hline & & $A_{212}$ & 7 & 8 & 9 & 6 \\
\hline & & $A_{221}$ & 7 & 8 & 8 & 7 \\
\hline & \multirow[t]{2}{*}{$A_{22}$} & $A_{222}$ & 9 & 8 & 8 & 9 \\
\hline & & $A_{223}$ & 9 & 8 & 9 & 9 \\
\hline & \multirow{6}{*}{$A_{23}$} & $A_{231}$ & 8 & 7 & 9 & 8 \\
\hline & & $A_{232}$ & 9 & 8 & 7 & 9 \\
\hline & & $A_{33}$ & 7 & 6 & 8 & 7 \\
\hline & & $A_{234}$ & 7 & 8 & 8 & 6 \\
\hline & & $A_{235}$ & 9 & 8 & 7 & 8 \\
\hline & & $A_{241}$ & 7 & 7 & 8 & 6 \\
\hline & \multirow[t]{2}{*}{$A_{24}$} & $A_{242}$ & 8 & 9 & 8 & 7 \\
\hline & & $A_{243}$ & 8 & 6 & 7 & 9 \\
\hline \multirow{12}{*}{$A_{3}$} & \multirow{2}{*}{$A_{31}$} & $A_{311}$ & 8 & 7 & 8 & 9 \\
\hline & & $A_{312}$ & 7 & 7 & 6 & 9 \\
\hline & \multirow{2}{*}{$A_{32}$} & $A_{321}$ & 7 & 8 & 6 & 8 \\
\hline & & $A_{322}$ & 8 & 6 & 7 & 9 \\
\hline & \multirow{3}{*}{$A_{33}$} & $A_{331}$ & 8 & 7 & 8 & 6 \\
\hline & & $A_{332}$ & 8 & 7 & 8 & 7 \\
\hline & & $A_{333}$ & 8 & 6 & 7 & 8 \\
\hline & \multirow{5}{*}{$A_{34}$} & $A_{341}$ & 7 & 8 & 9 & 7 \\
\hline & & $A_{342}$ & 8 & 7 & 6 & 8 \\
\hline & & $A_{343}$ & 9 & 8 & 7 & 9 \\
\hline & & $A_{344}$ & 7 & 7 & 8 & 9 \\
\hline & & $A_{345}$ & 8 & 7 & 8 & 9 \\
\hline
\end{tabular}
so the scale value vector of the assessed grey class is

$$
D=\left(d_{1}, d_{2}, \ldots, d_{g}\right)
$$

The comprehensive score of the performance is

$$
\tau=B D^{T} \text {. }
$$

TABLE 3: Expert score statistics.

4.2. Application Analysis of the Assessment Model. This paper takes one prison physical protection system as an example. It has just completed the overall transformation of the physical protection system, with noticeable improvement on defense by people, by material, and by technology. Its equipment is also quite advanced. According to the index system, the evaluation model and operation method are constructed (see above).

Then a group of experts are organized to score each index, in accordance with the previously constructed effectiveness evaluation index system of the prison physical protection system. The result is shown in Table 3. 
$T$ is the judgment matrix of the effectiveness evaluation index $A$ (first-level index) of the prison physical protection system, and $T_{1}, T_{2}, T_{3}$ are the judgment matrix of the effectiveness evaluation index $A_{1}, A_{2}, A_{3}$ (second-level index); $T_{11}, T_{12}, T_{13}, \ldots, T_{34}$ are the judgment matrix of the effectiveness evaluation index $A_{11}, A_{12}, A_{13}, \ldots, A_{34}$ (thirdlevel index). The judgment matrix of indexes belonging to each level is as follows:

$$
\begin{aligned}
& T=\left[\begin{array}{ccc}
1 & \frac{1}{3} & 3 \\
3 & 1 & 5 \\
\frac{1}{3} & \frac{1}{5} & 1
\end{array}\right] \\
& T_{1}=\left[\begin{array}{cccc}
1 & 4 & 6 & 2 \\
\frac{1}{4} & 1 & 2 & \frac{1}{2} \\
\frac{1}{6} & \frac{1}{2} & 1 & \frac{1}{4} \\
\frac{1}{2} & 2 & 4 & 1
\end{array}\right] \\
& T_{2}=\left[\begin{array}{cccc}
1 & \frac{1}{3} & 3 & 4 \\
3 & 1 & 4 & 5 \\
\frac{1}{3} & \frac{1}{4} & 1 & 2 \\
\frac{1}{4} & \frac{1}{5} & \frac{1}{2} & 1
\end{array}\right] \\
& T_{3}=\left[\begin{array}{cccc}
1 & 5 & 3 & 3 \\
\frac{1}{5} & 1 & \frac{1}{2} & \frac{1}{2} \\
\frac{1}{3} & 2 & 1 & 1 \\
\frac{1}{3} & 2 & 1 & 1
\end{array}\right] \\
& T_{11}=\left[\begin{array}{ll}
1 & \frac{1}{4} \\
4 & 1
\end{array}\right] \\
& T_{12}=\left[\begin{array}{ccc}
1 & \frac{1}{3} & 2 \\
3 & 1 & 5 \\
\frac{1}{2} & \frac{1}{5} & 1
\end{array}\right] \\
& T_{13}=\left[\begin{array}{ll}
1 & \frac{1}{5} \\
5 & 1
\end{array}\right] \\
& T_{14}=\left[\begin{array}{ll}
1 & \frac{1}{3} \\
3 & 1
\end{array}\right] \\
& T_{21}=\left[\begin{array}{ll}
1 & 3 \\
\frac{1}{3} & 1
\end{array}\right]
\end{aligned}
$$$$
T_{22}=\left[\begin{array}{ccc}
1 & 5 & 3 \\
\frac{1}{5} & 1 & \frac{1}{3} \\
\frac{1}{3} & 3 & 1
\end{array}\right]
$$$$
T_{23}=\left[\begin{array}{cccc}
1 & 3 & 5 & 2 \\
\frac{1}{3} & 1 & 3 & \frac{1}{3} \\
\frac{1}{5} & \frac{1}{3} & 1 & \frac{1}{5} \\
\frac{1}{2} & 3 & 5 & 1
\end{array}\right]
$$$$
T_{24}=\left[\begin{array}{ccc}
1 & 2 & 3 \\
\frac{1}{2} & 1 & 2 \\
\frac{1}{3} & \frac{1}{2} & 1
\end{array}\right]
$$$$
T_{31}=\left[\begin{array}{cc}
1 & 3 \\
\frac{1}{3} & 1
\end{array}\right]
$$$$
T_{32}=\left[\begin{array}{cc}
1 & 3 \\
\frac{1}{3} & 1
\end{array}\right]
$$$$
T_{33}=\left[\begin{array}{ccc}
1 & 1 & 3 \\
1 & 1 & 3 \\
\frac{1}{3} & \frac{1}{3} & 1
\end{array}\right]
$$$$
T_{34}=\left[\begin{array}{ccccc}
1 & 3 & 3 & 5 & 5 \\
\frac{1}{3} & 1 & 1 & 3 & 3 \\
\frac{1}{3} & 1 & 1 & 3 & 3 \\
\frac{1}{5} & \frac{1}{3} & \frac{1}{3} & 1 & 1 \\
\frac{1}{5} & \frac{1}{3} & \frac{1}{3} & 1 & 1
\end{array}\right] .
$$

Calculate the weight vector of indexes belonging to each level and verify the consistency. The result is shown in Table 4.

Based on the $T$ score matrix and $\omega$ weight vector, using the total grey assessment coefficient calculation formula (13) and formulas (15)-(18) of comprehensive evaluation values of indexes of all levels calculates the results and then puts the value into the comprehensive evaluation formula (20) and finally figures out the comprehensive evaluation value of prison security system effectiveness $\tau=7.4630$. It is very clear after making comparison between the value of $\tau$ and the ranking Table 2 that the result of the effectiveness evaluation of this prison physical security protection system is "relatively good." 
TABLE 4: Weight vector and consistency judgment.

\begin{tabular}{lcc}
\hline Weight vector & CR & $\begin{array}{c}\text { Consistency } \\
\text { judgment }\end{array}$ \\
\hline$\omega=(0.2605,0.6333,0.1062)^{T}$ & 0.0334 & Satisfied \\
$\omega_{1}=(0.5821,0.1194,0.0597,0.2388)^{T}$ & 0.0299 & Satisfied \\
$\omega_{2}=(0.3391,0.4499,0.1319,0.0790)^{T}$ & 0.0756 & Satisfied \\
$\omega_{3}=(0.6015,0.0797,0.1594,0.1594)^{T}$ & 0.0260 & Satisfied \\
$\omega_{11}=(0.2,0.8)^{T}$ & 0 & Satisfied \\
$\omega_{12}=(0.2299,0.6479,0.1222)^{T}$ & 0.0032 & Satisfied \\
$\omega_{13}=(0.1667,0.8333)^{T}$ & 0 & Satisfied \\
$\omega_{14}=(0.25,0.75)^{T}$ & 0 & Satisfied \\
$\omega_{21}=(0.75,0.25)^{T}$ & 0 & Satisfied \\
$\omega_{22}=(0.6333,0.1062,0.2605)^{T}$ & 0.0334 & Satisfied \\
$\omega_{23}=(0.5224,0.1274,0.0497,0.3005)^{T}$ & 0.0764 & Satisfied \\
$\omega_{24}=(0.5390,0.2972,0.1638)^{T}$ & 0.0079 & Satisfied \\
$\omega_{31}=(0.75,0.25)^{T}$ & 0 & Satisfied \\
$\omega_{32}=(0.75,0.25)^{T}$ & 0 & Satisfied \\
$\omega_{33}=(0.4286,0.4286,0.1428)^{T}$ & 0 & Satisfied \\
$\omega_{34}=$ & & \\
$(0.4624,0.1952,0.1952,0.0737,0.0737)^{T}$ & 0.0124 & Satisfied \\
\hline
\end{tabular}

From the integrative assessment values of the effectiveness evaluation to the prison physical protection system, two conclusions can be drawn: (a) the protection system is in the activating state and can be put into use any time since the value indicates being relatively good. So, it can be safely stated this evaluation model can really help to solve the practical problems. (b) Through observation and comparison, the consistency of the weight vectors at different levels is satisfied, which indicates that all the experts' judgments are consistent and so the assessment results are reliable.

Based on the calculation and analysis above, we can see clearly that the model built up here can be effectively used to reduce the influence of subjective factors on the effectiveness evaluation to the prison physical protection system. Thus, we can conclude that this model, integrated by the static attributes and dynamic attributes, is typically characterized by its accuracy and feasibility, which can provide effective reference for the effectiveness evaluation to the security protection system in public safety departments.

\section{Conclusion}

This paper, distinguished from the assessment mode of the traditional effectiveness evaluation of the physical protection system, in which the application area is not clear and the assessment index is relatively general, applied the effectiveness evaluation of the physical protection system into the prison system to explore the more accurate and feasible methods in evaluating the performances produced in a special area. And by arranging and integrating the key elements of the performance of the prison physical protection system, the factors of its assessment have been improved, by means of constructing an assessment index system based on the informationization, the action efficiency, and the sustainability of the system of the physical protection system integrated with the static attributes and dynamic attributes. As a result, a corresponding mathematical model has been established so that a better solution to the problem of a lack of content and indexes in the effectiveness evaluation and rationality of the assessment has been obtained. Based on the grey scale analysis method, we obtained a new assessment model by collecting scores of a group of experts on each index, constructing the weight vector of different grey classes, calculating the total grey assessment coefficient of each level's index, and acquiring the integrative assessment value of the performance of the prison physical protection system.

Besides, the result of this research seems to imply that the combination use of qualitative and quantitative indexes can effectively reduce the subjective and random factors interfering with the assessment process and results. It is testified by the example that the evaluation model and its algorithm are effective and can improve the scientific nature and validity of the effectiveness evaluation to the prison physical protection system.

\section{Conflicts of Interest}

The author declares that they have no conflicts of interest.

\section{Acknowledgments}

This work is funded by the Fundamental Research Funds for the Central Universities under Grant LGZD201602 and Teaching Reform Research Project YB17019. Dr. Yin Ke, who graduated from Nanjing University of Technology and majored in safety engineering and risk control, is now a senior lecturer at Nanjing Forest Police Academy.

\section{References}

[1] D. P. Gallegos and E. J. Bonano, "Consideration of uncertainty in the performance assessment of radioactive waste disposal from an international regulatory perspective," Reliability Engineering \& System Safety, vol. 42, no. 2-3, pp. 111-123, 1993.

[2] A. Paridaa and U. Kumara, "Integrated strategic asset performance assessment," in proceedings of the 4th World Congress on Engineering Asset Management: Engineering Asset Lifecycle Management, WCEAM, Athens, Greece, 2009.

[3] X. Zhenmin and D. Peilong, "Method of anti-jamming effectiveness evaluation for distributed radar based on AHP," Modern Radar, vol. 39, pp. 77-83, 2017.

[4] M. Bian-feng and Q. Xiao-guang, "Operational effectiveness evaluation of networking surface-to-air missile based on adc model," Modern Defence Technology, vol. 45, pp. 28-34, 2017.

[5] X. Xiaogang, "On constructing prevention mode of security from the trend of the prison situation perspective," Journal of Anhui Vocational College of Police Officers, vol. 11, pp. 9-13, 2012.

[6] A. V. Filimonov and A. Leus, "Efficiency evaluation of physical protection system," in Proceedings of the 2011 International Conference on Business, Engineering and Industrial Applications, ICBEIA 2011, pp. 216-220, Malaysia, June 2011.

[7] P. Xu, Y. Deng, X. Su, X. Chen, and S. Mahadevan, "An evidential approach to physical protection system design," Safety Science, vol. 65, pp. 125-137, 2014. 
[8] A. A. Wadoud, A. S. Adail, and A. A. Saleh, "Physical protection evaluation process for nuclear facility via sabotage scenarios," Alexandria Engineering Journal, 2017.

[9] G. Xi, H. Ruimin, P. Yongjun, and D. Jingjing, "The risk assessment of crime prevention system based on risk entropy model," in Proceedings of the 2nd International Conference on Computer Research and Development, ICCRD, pp. 681-685, Malaysia, May 2010.

[10] E. Lagendijk and D. Ryan, "From CSG to LNG: modeling and understanding key subsurface uncertainties for the development of a surat basin opportunity, in queensland, australia," in Proceedings of the Canadian Unconventional Resources and International Petroleum Conference, pp. 1873-1885, can, October 2010.

[11] L. Hongtao, "The whole solution to prison security protection and informatization," Control Automation, vol. 28, pp. 130-132, 2012.

[12] K. Qiao, "Study on effectiveness evaluation method of social security dynamic prevention system," Journal of Chinese Peoples Public Security University (Science and Technology, vol. 2, pp. 5257, 2009.

[13] C. Han, "Analysis of operational command effectiveness index based on Information Network," Information \& Communications, vol. 22, pp. 92-94, 2012.

[14] L. Guizhi, "Analysis of effectiveness evaluation index system of prison security comprehensive management system," Intelligent Processing and Application, vol. 12, pp. 42-45, 2016.

[15] F. Argenti, G. Landucci, V. Cozzani, and G. Reniers, "A study on the performance assessment of anti-terrorism physical protection systems in chemical plants," Safety Science, vol. 94, pp. 181-196, 2017.

[16] D. Mathivathanan, K. Govindan, and A. N. Haq, "Exploring the impact of dynamic capabilities on sustainable supply chain firm's performance using grey-analytical hierarchy process," Journal of Cleaner Production, vol. 147, pp. 637-653, 2017.

[17] L. Ning and H. CHEN, "Grey analytic hierarchy process based evaluation of battle command efficiency," Journal of Ordnance Equipment Engineering, vol. 38, pp. 22-26, 2017. 


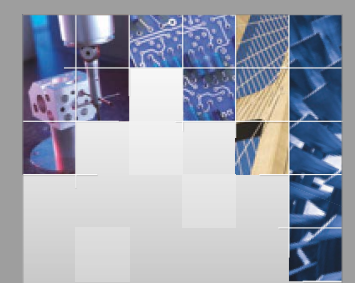

\section{Enfincering}
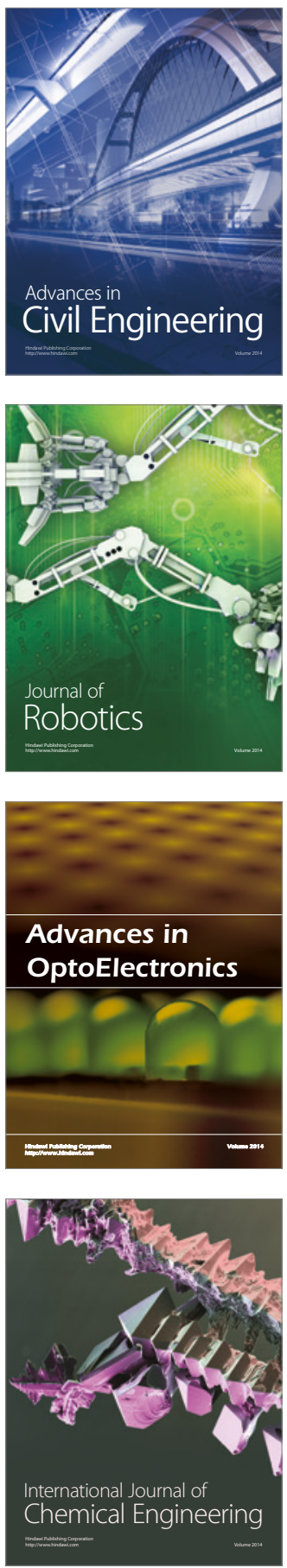

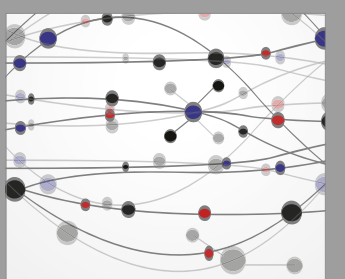

The Scientific World Journal

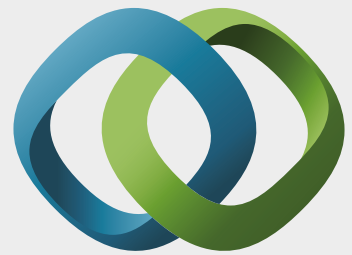

\section{Hindawi}

Submit your manuscripts at

https://www.hindawi.com
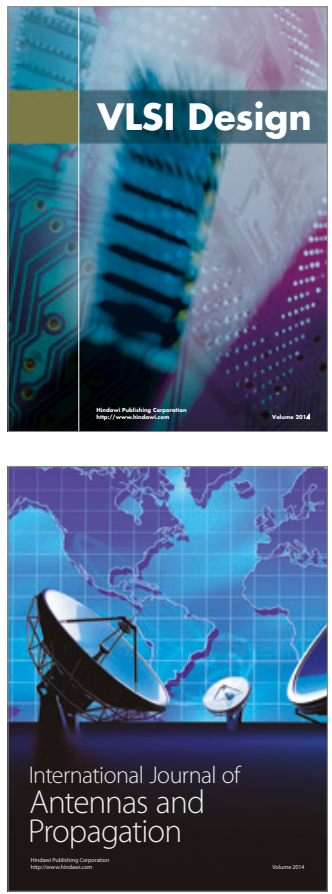

\section{Rotating}

Machinery
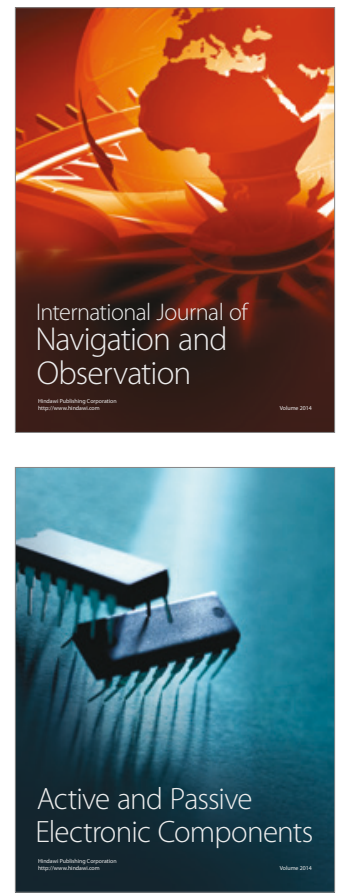
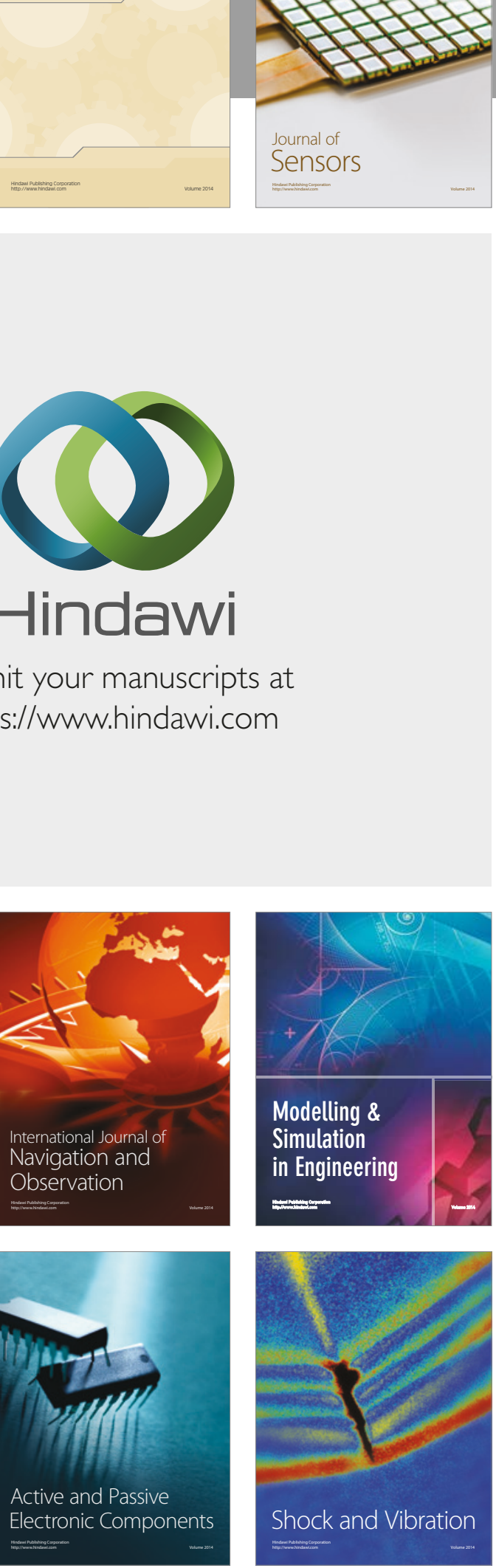
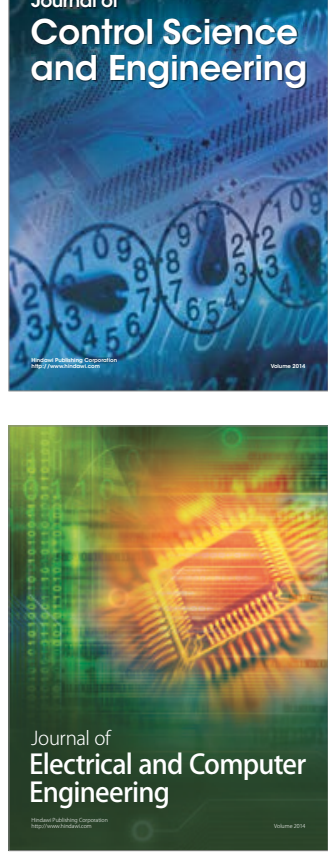

Distributed

Journal of

Control Science

and Engineering
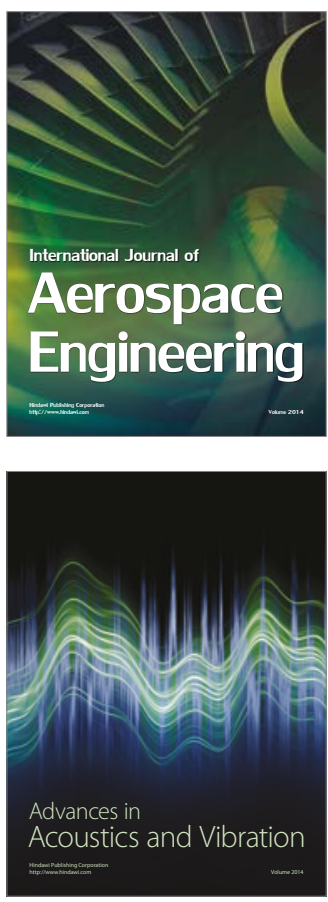

Sensor Networks 